\title{
A comparison of pulmonary function in bronchial asthma and chronic obstructive bronchitis
}

\author{
K. N. V . PALMER, M . L. DIA MEN T \\ Departments of Medicine and Physiology, University of Aberdeen
}

\begin{abstract}
The dynamic and static lung volumes, arterial blood-gas tensions, and single-breath carbonmonoxide transfer factor have been compared in 72 asthmatic and 45 bronchitic patients with airways obstruction of comparable severity to determine which measurements might be used to discriminate between the two diseases. The forced vital capacity, total lung capacity, arterial carbon-dioxide tension, and transfer factor were useful in this respect. Thus, in a patient with airways obstruction the finding of a low \% predicted FVC $(<70)$ and a low \% predicted Dico $(<50)$ with a relatively normal \% predicted TLC and a raised $\mathrm{PaCO}_{2}$ is strongly suggestive of chronic obstructive bronchitis, whereas the finding of a relatively normal \% predicted FVC and a high \% predicted TLC $(>115)$ with a nearly normal Dico and a normal or low $\mathrm{PaCO}_{2}$ is most compatible with a diagnosis of bronchial asthma.
\end{abstract}

Generalized obstruction of the small bronchial airways is a characteristic feature of both bronchial asthma and chronic obstructive bronchitis. This leads to important changes in dynamic and static lung volumes, blood-gas tensions, and transfer factor and we have reported how these measurements are altered in both asthmatic and bronchitic subjects (Palmer and Diament, 1969a, b). However, because the functional changes in the two diseases are similar, a sharp separation based on physiological abnormalities is not always possible, and to determine whether any particular measurement or group of measurements could be used to differentiate between them we have here compared the changes in pulmonary function in the two diseases. Because our asthmatic subjects were younger and there were more females than in the bronchitic group, it has been necessary to standardize the measurements by first determining the predicted normal value for each patient (based on age, sex, height, and weight) and then expressing the absolute measurements as a percentage of the predicted normal values.

\section{PATIENTS AND METHODS}

There were 117 subjects-72 asthmatic and 45 obstructive bronchitic. The mean ages, heights, and weights $( \pm S D)$ are shown in Table I. Forty asthmatics $(55.5 \%)$ and nine bronchitics $(20.0 \%)$ were women. The asthmatics had a history of attacks of acute airways obstruction with little or minimal disability between attacks. They all had at some time sputum or blood eosinophilia and the majority had positive skin tests to various allergens. The bronchitics were for the most part heavy cigarette smokers who had a long history of productive cough and attacks of breathlessness, usually associated with purulent sputum -most often after upper respiratory tract infections. None had blood or sputum eosinophilia.

The methods used for obtaining the dynamic and static lung volumes, blood-gas tensions, and transfer factor were as described previously (Palmer and Diament, 1969a, b). For purposes of comparison the mean values are expressed as percentages of the predicted normal values using the data of the Committee on Rating of Mental and Physical Impairment (1965) for dynamic lung volumes, of Needham, Rogan, and McDonald (1954) for static lung volumes, of Ogilvie, Forster, Blakemore, and Morton (1957) for the singlebreath carbon monoxide transfer factor, and our own data for arterial blood-gas tensions (Diament and Palmer, 1969). The prediction formulae used for the dynamic lung volumes are dependent on age, sex, and height, those for the static lung volumes on age, sex, height, and weight, the arterial blood-gas tensions on age and sex, and the transfer factor on height alone. The only significant differences between asthmatics and bronchitics were mean age and sex; there was no significant difference between mean weight and height.

\section{RESULTS}

Table I shows the mean values $( \pm S D)$ for dynamic lung volumes [forced vital capacity (FVC), forced expiratory volume in 1 second $\left(F E V_{1}\right)$, and $\mathrm{FEV}_{1}$ expressed as a percentage of FVC $\left(\mathrm{FEV}_{1} \%\right)$ ], static lung volumes [total lung 
capacity (TLC), functional residual capacity (FRC), residual volume (RV), and RV/TLC\%], arterial oxygen tension $\left(\mathrm{PaO}_{2}\right)$ and transfer factor (Dlco), expressed as a percentage of the individual predicted normal values. The mean arterial carbon dioxide tension $\left(\mathrm{PaCO}_{2}\right)$ is given in absolute values since it does not vary with age, sex or height (Diament and Palmer, 1969).

\section{T A B LE I}

MEAN \% PREDICTED DYNAMIC AND STATIC LUNG VOLUMES, ARTERIAL BLOOD-GAS TENSIONS (mm. Hg), AND TRANSFER FACTOR (ml./min./mm. Hg) ( \pm SD ) IN 72 SUBJECTS

\begin{tabular}{|c|c|c|c|}
\hline & Asthmatics & Bronchitics & $\mathbf{P}$ \\
\hline 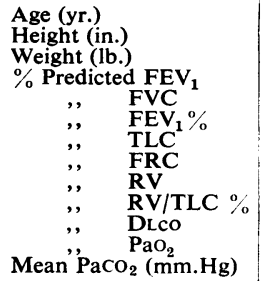 & 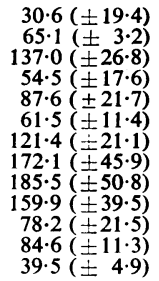 & 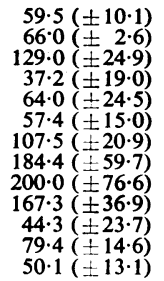 & $\begin{aligned}<0.001 \\
\text { N.S. } \\
\text { N.S. } \\
<0.001 \\
<0.001 \\
\text { N.S. } \\
<0.001 \\
\text { N.S. } \\
\text { N.S. } \\
\text { N.S. } \\
<0.001 \\
\text { N.S. } \\
<0.001\end{aligned}$ \\
\hline
\end{tabular}

N.S. $=$ not significant

Whilst there was no significant difference in $\mathrm{FEV}_{1} \%$ and therefore in the degree of airway obstruction between the asthmatics and bronchitics, both FVC and $\mathrm{FEV}_{1}$ were significantly lower in the bronchitics. Of the static lung volumes, TLC was significantly higher in the asthmatics, but whilst FRC, RV, and RV/TLC\% were all much increased from normal in both, there was no significant difference in the extent of the increase between them. Both groups had hypoxaemia of comparable degree, but the $\mathrm{PaCO}_{2}$ was significantly higher in the bronchitics The Dico was slightly reduced in the asthmatics but to a significantly greater degree in the
bronchitics.

The results of these tests, depending on the $\vec{\circ}$ degree of airway obstruction, again expressed as $\vec{t}$ $\%$ predicted normal values, are shown in Table II There are three groups: mild airway obstruction $₹$ $\mathrm{FEV}_{1} \%$ 55-69; moderate, $\mathrm{FEV}_{1} \%$ 40-54; and severe, $\mathrm{FEV}_{1} \%<40$. There was a greater reduc tion in \% predicted FVC and $\mathrm{FEV}_{1}$ in bronchitics. than in asthmatics for all grades of airwaye obstruction, this change reaching significant levelso for FVC in the mild and severe groups but only in the severe group for $\mathrm{FEV}_{1}$. The \% predictede TLC was greater in the asthmatic than in the bronchitic in the mild and moderate groups, butom the differences in the other static lung volumes were not significant. The $\mathrm{PaO}_{2}$ showed a progres-e sive fall with increasing airway obstruction in botho diseases, but this was accompanied by a rising $\mathrm{PaCO}_{2}$ level in the bronchitic group, whereas the

T A B L E I I I

EFFECT OF BRONCHODILATOR ON MEAN FEV 1 (LITRES A.T.P.S.) $( \pm$ SD)

\begin{tabular}{|c|c|c|c|}
\hline & & Asthmatics & Bronchitics \\
\hline $\begin{array}{l}F^{F E V_{1}} \text { pre-bronchodilator } \\
\text { FEV }_{1} \text { post-bronchodilator } \\
\text { Mean increase in FEV } \\
\text { Mean \% increase in FEV }\end{array}$ & $\begin{array}{l}\cdots \\
\cdots \\
\cdots\end{array}$ & $\begin{array}{c}1.56( \pm 0.61) \\
1.88( \pm 0.70) \\
(\mathrm{P}<0.001) \\
0.32( \pm 0.25) \\
21.9( \pm 20.4)\end{array}$ & $\begin{array}{c}0.98( \pm 0.49) \\
1.11( \pm 0.54) \\
(\mathrm{P}<0.001) \\
0.13( \pm 0.14) \\
(\mathrm{P}<0.001) \\
14.6( \pm 13.3) \\
(\mathrm{P}<0.025)\end{array}$ \\
\hline
\end{tabular}

T A B L E I I

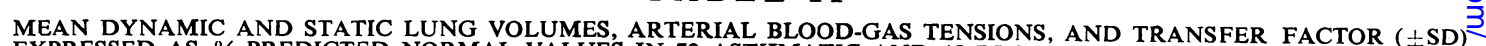
EXPRESSED AS \% PREDICTED NORMAL VALUES IN 72 ASTHMATIC AND 45 BRONCHITIC PATIENTS WITH AIRWAYO
OBSTRUCTION OF INCREASING SEVERITY

\begin{tabular}{|c|c|c|c|c|c|c|c|c|c|}
\hline & \multicolumn{2}{|c|}{$\begin{array}{c}\text { Mild } \\
\text { FEV }_{1} \% 55-69\end{array}$} & \multirow{3}{*}{$P$} & \multicolumn{2}{|c|}{$\begin{array}{c}\text { Moderate } \\
\text { FEV }_{1} \% 40-54\end{array}$} & \multirow{3}{*}{$\mathbf{P}$} & \multicolumn{2}{|c|}{$\begin{array}{c}\text { Severe } \\
\text { FEV }_{1} \%<40\end{array}$} & \multirow{3}{*}{$\mathbf{P}$} \\
\hline & Asthmatics & Bronchitics & & Asthmatics & Bronchitics & & Asthmatics & Bronchitics & \\
\hline No. & 29 & 9 & & 34 & 21 & & 9 & 15 & \\
\hline $\begin{array}{l}\text { Age (yr.) } \\
\text { Height (in.) } \\
\text { Weight (lb.) }\end{array}$ & $\begin{array}{r}40 \cdot 8( \pm 15 \cdot 7) \\
65 \cdot 3( \pm 2 \cdot 8) \\
136.9( \pm 20 \cdot 2) \\
\end{array}$ & $\begin{array}{c}63.8( \pm 8 \cdot 9) \\
66.5( \pm 2 \cdot 4) \\
131 \cdot 3( \pm 21 \cdot 6)\end{array}$ & $\begin{array}{l}<0.001 \\
\text { N.S. } \\
\text { N.S. }\end{array}$ & $\begin{array}{r}39 \cdot 7( \pm 12 \cdot 0) \\
65 \cdot 5( \pm 3 \cdot 1) \\
141 \cdot 5( \pm 27 \cdot 7) \\
\end{array}$ & $\begin{array}{c}61 \cdot 1( \pm 10 \cdot 2) \\
66 \cdot 1( \pm 2 \cdot 9) \\
131 \cdot 5( \pm 25 \cdot 4)\end{array}$ & $\begin{array}{c}<0.001 \\
\text { N.S. } \\
\text { N.S. }\end{array}$ & $\begin{array}{c}37.6( \pm 14.7) \\
64.9( \pm 3.5) \\
131.3( \pm 15.6)\end{array}$ & $\begin{array}{c}54 \cdot 4( \pm 9 \cdot 8) \\
65 \cdot 4( \pm 2 \cdot 5) \\
118 \cdot 7( \pm 23 \cdot 7)\end{array}$ & $\begin{array}{c}<0.01 \\
\text { N.S. } \\
\text { N.S. }\end{array}$ \\
\hline $\begin{array}{l}\text { \% predicted } \\
\text { FEV }_{1} \\
\text { FVC } \\
\text { FEV } 1 \% \\
\text { TLC } \\
\text { FRC } \\
\text { RV } \\
\text { RV/TLC } \\
\text { DLco } \\
\text { PaO }_{2} \\
\text { PaCO }_{2} \\
\text { (mm.Hg) }\end{array}$ & $\begin{array}{c}67 \cdot 0( \pm 16 \cdot 1) \\
94 \cdot 6( \pm 20 \cdot 8) \\
72 \cdot 4( \pm 5 \cdot 2) \\
117 \cdot 1( \pm 25 \cdot 6) \\
163 \cdot 1( \pm 37 \cdot 6) \\
161.9( \pm 40 \cdot 9) \\
145 \cdot 0( \pm 28 \cdot 3) \\
86.3( \pm 16 \cdot 9) \\
89.0( \pm 69 \cdot 3) \\
37 \cdot 8( \pm 3 \cdot 6)\end{array}$ & $\begin{array}{c}51 \cdot 2( \pm 24 \cdot 0) \\
66 \cdot 8( \pm 28 \cdot 1) \\
80 \cdot 4( \pm 9 \cdot 3) \\
97 \cdot 1( \pm 24 \cdot 1) \\
151 \cdot 7( \pm 58 \cdot 8) \\
152 \cdot 8( \pm 49 \cdot 2) \\
147 \cdot 5( \pm 15 \cdot 3) \\
38 \cdot 5( \pm 26 \cdot 6) \\
86 \cdot 3( \pm 11 \cdot 5) \\
41 \cdot 1( \pm 7 \cdot 2)\end{array}$ & $\begin{array}{l}\text { N.S. } \\
<0.01 \\
<0.02 \\
<0.05 \\
\text { N.S. } \\
\text { N.S. } \\
\text { N.S. } \\
<0.01 \\
\text { N.S. } \\
\text { N.S. }\end{array}$ & $\begin{array}{c}49 \cdot 3( \pm 12 \cdot 2) \\
82 \cdot 8( \pm 22 \cdot 5) \\
57 \cdot 3( \pm 5 \cdot 2) \\
123 \cdot 7( \pm 18 \cdot 1) \\
173 \cdot 8( \pm 49 \cdot 8) \\
192 \cdot 3( \pm 48 \cdot 4) \\
163 \cdot 5( \pm 42 \cdot 7) \\
75 \cdot 4( \pm 22 \cdot 4) \\
82.6( \pm 9 \cdot 7) \\
40.7( \pm 6 \cdot 1)\end{array}$ & $\begin{array}{c}41 \cdot 7( \pm 14 \cdot 9) \\
70 \cdot 7( \pm 24 \cdot 5) \\
58 \cdot 6( \pm 4 \cdot 7) \\
107.9( \pm 16 \cdot 4) \\
179 \cdot 1( \pm 43.4) \\
185 \cdot 4( \pm 49 \cdot 6) \\
160 \cdot 7( \pm 32 \cdot 3) \\
48.6( \pm 25 \cdot 2) \\
81 \cdot 1( \pm 13 \cdot 2) \\
47 \cdot 2( \pm 8 \cdot 7)\end{array}$ & $\begin{array}{l}\text { N.S. } \\
\text { N.S. } \\
\text { N.S. } \\
<0.005 \\
\text { N.S. } \\
\text { N.S. } \\
\text { N.S. } \\
<\text { 0.001 } \\
\text { N.S. } \\
<0.01\end{array}$ & $\begin{array}{c}34 \cdot 2( \pm 9 \cdot 1) \\
81 \cdot 6( \pm 21 \cdot 8) \\
42 \cdot 1( \pm 2 \cdot 8) \\
126 \cdot 2( \pm 14 \cdot 0) \\
198 \cdot 4( \pm 51 \cdot 4) \\
235 \cdot 9( \pm 47 \cdot 9) \\
194 \cdot 3( \pm 36 \cdot 3) \\
63 \cdot 1( \pm 22 \cdot 3) \\
79 \cdot 1( \pm 17 \cdot 4) \\
39 \cdot 9( \pm 4 \cdot 2)\end{array}$ & $\begin{array}{l}22.6( \pm 10.0) \\
52.8( \pm 19 \cdot 3) \\
41.8( \pm 5 \cdot 3) \\
113.6( \pm 23 \cdot 7) \\
206.0( \pm 84.6) \\
252.2( \pm 96.4) \\
190.6( \pm 42.6) \\
41.9( \pm 21.2) \\
73.5( \pm 16.4) \\
60.5( \pm 15 \cdot 7)\end{array}$ & $\begin{array}{l}<0.01 \\
<0.005 \\
\text { N.S. } \\
\text { N.S. } \\
\text { N.S. } \\
\text { N.S. } \\
\text { N.S. } \\
\text { N.S. } \\
\text { N.S. } \\
<0.001\end{array}$ \\
\hline
\end{tabular}


$\mathrm{PaCO}_{2}$ remained low or normal in the asthmatics. The Dlco fell in the asthmatics somewhat as airway obstruction increased, but in the bronchitics it remained at a fixed low level irrespective of the degree of airway obstruction.

Table III shows the changes in $\mathrm{FEV}_{1}$ following the aerosol inhalation of a bronchodilator in the two groups. In both there was a significant rise in FEV, after the drug, the rise in the asthmatics being significantly greater than in the bronchitics both as an absolute and percentage increase.

\section{DISCUSSION}

A basic difficulty in comparing the changes in pulmonary function in asthmatic and bronchitic patients is that asthmatics are frequently young and female, whereas bronchitics are predominantly older men, and most pulmonary function measurements are dependent on the variables, age, sex, and height, and in some instances weight also. To overcome this difficulty we have expressed the measurements of the dynamic and static lung volumes, $\mathrm{PaO}_{2}$ and DLco as percentages of the individual predicted normal value for each patient.

Although the degree of airways obstruction did not differ between asthmatics and bronchitics, both $\%$ predicted FVC and FEV 1 were significantly lower in the bronchitics, this difference being greater for FVC (23.6, SE 0.92) than for FEV $(17 \cdot 3$, SE $0 \cdot 81)$. The \% predicted FVC, however, was still greater in severe asthma than it was in mild bronchitis, whereas the \% predicted FEV tended to fall to the same extent in both, depending on the extent of the airway obstruction. We think, therefore, that the \% predicted FVC is a better measurement than \% predicted $\mathrm{FEV}_{1}$ to separate the two diseases. This is in keeping with our observations that $\mathrm{FEV}_{1}$ reflects both obstructive and restrictive elements of ventilatory impairment whereas FVC is not a measure of airway obstruction but indicates solely a restrictive ventilatory defect secondary to lung hyperinflation which develops progressively as airway obstruction increases (Palmer and Diament, 1968a, b). We have also suggested that RV/TLC $\%$ is the best index of such hyperinflation in both diseases (Palmer and Diament, 1969a, b), but although the $\mathrm{RV} / \mathrm{TLC} \%$ was much increased in both the asthmatics and bronchitics, the extent of the increase did not differ between them. This means that for a comparable degree of hyperinflation, bronchitic patients will have a greater restrictive impairment than do asthmatics. This indicates an additional factor leading to restrictive ventilatory impairment in bronchitis and may well reflect the presence of peribronchial fibrosis. This could also explain why the TLC was significantly larger in asthmatics than in bronchitics.

Whilst FVC, $\mathrm{FEV}_{1}$, and TLC were significantly different between asthmatics and bronchitics, the indices of hyperinflation (FRC, RV, RV/TLC\%) were not different and therefore have little or no value in distinguishing between the two diseases. $\mathrm{PaCO}_{2}$ was significantly higher in bronchitics than in asthmatics and rose in the bronchitics but not in the asthmatics as the airway obstruction increased. It is of interest that there was no significant difference in $\mathrm{PaO}_{2}$ for the groups as a whole or for any of the sub-groups. This indicates that, whatever the physiological difference may be between asthma and bronchitis, it does not affect the degree of hypoxaemia.

For comparable airway obstruction Deco is reported to be well preserved in patients with chronic obstructive bronchitis but to fall progressively when this disease is associated with emphysema (Fletcher, Hugh-Jones, McNicol, and Pride, 1963). Burrows, Niden, Barclay, and Kasik (1965) found low mean values for this test in subjects with irreversible airways obstruction and there was some relationship between the fall in Dico and the severity of the airway obstruction. We found the mean Duco to be less than $50 \%$ of predicted normal value in the bronchitics and it remained at this low level whatever the degree of airway obstruction. Deco is generally described as being normal in asthma (Meisner and Hugh-Jones, 1968; Bedell and Ostigury, 1967). We found the mean \% predicted Duco was reduced somewhat in asthma and that it fell further as airway obstruction increased. The Dlco, therefore, in our experience is quite different in asthma and obstructive bronchitis. It is fixed at a nearly constant low level in obstructive bronchitis, but although it is slightly reduced in mild asthma it continues to fall with increasing airway obstruction. We regard this as a useful test to differentiate the two diseases.

Airway obstruction was reduced by aerosol bronchodilators in both diseases. In asthmatics there was a mean rise in $\mathrm{FEV}_{1}$ of over $20 \%$, but in bronchitics the mean rise was only $15 \%$, which is significantly less than that for the asthmatics (Table III).

We conclude from our findings that for equivalent degrees of airway obstruction there are significant differences beween asthmatics and bronchitics in several of the pulmonary function 
measurements, and we suggest that these measurements may be used as an aid in the clinical differentiation of the two diseases. It happens that one measurement each of the static lung and dynamic lung volumes and the blood-gas tensions together with the transfer factor turns out to be a useful discriminator in this respect. Thus, in a patient with airways obstruction, the finding of a low $\%$ predicted FVC $(<70)$ and a low \% predicted Deco $(<50)$ with a relatively normal \% predicted TLC and a raised $\mathrm{PaCO}_{2}$ is strongly suggestive of chronic obstructive bronchitis, whereas the finding of a relatively normal $\%$ predicted FVC and a high \% predicted TLC $(>115)$ with a nearly normal DLco and a normal or low $\mathrm{PaCO}_{2}$ is most compatible with a diagnosis of bronchial asthma.

Requests for reprints should be addressed to K. N. V. Palmer, University Depariment of Medicine. Foresterhill. Aberdeen AB9 2ZD.

\section{REFERENCES}

Bedell, G. N., and Ostigury, G. L. (1967). Transfer factor for carb monoxide in patients with airways obstruction. Clin. Sci., 32, 23פ

Burrows, B., Niden, A. H., Barclay, W. R., and Kasik, J. E. (1965 Chronic obstructive lung disease. Amer. Rev. resp. Dis., 91, 665

Committee on Rating of Mental and Physical Impairment. Guid $₫$ (1965). J. Amer. med. Ass., 194,919.

Diament, M. L., and Palmer, K. N. V. (1969). An analysis of pre operative $\mathrm{PaO}_{2}$ in a general surgical population. Thorax, 24, 120

Fletcher, C. M., Hugh-Jones, P., McNicol, M. W., and Pride, N. Bं (1963). The diagnosis of pulmonary emphysema in the presence of chronic bronchitis. Quart. J. Med., 32, 33.

Meisner, P., and Hugh-Jones, P. (1968). Pulmonary function bronchial asthma. Brit. med. $J ., 1,470$.

Needham, C. D., Rogan, M. C., and McDonald, I. (1954). Norm values for lung volumes, intrapulmonary gas-mixing, an
maximum breathing capacity. Thorax, 9,313 .

Ogilvie, C. M., Forster, R. E., Blakemore, W. S., and Morton, J IT (1957). A standardized breath holding technique for the clinic measurement of the diffusing capacity of the lung for carbon monoxide. J. clin. Invest., 36, 1.

Palmer, K. N. V., and Diament, M. L. (1968a). Hypoxaemia bronchial asthma. Lancet 1, 318 and 595 .

- (1968b). Relative contributions of obstructive and restrietive ventilatory impairment in the production of hypoxaemi and hypercapnia in chronic bronchitis. Ibid., 1, 1233 . (1969a). Dynamic and static lung volumes and blood-g tensions in bronchial asthma. Ibid., 1, 591.

(1969b). Dynamic and static lung volumes, blood gas tensions, and transfer factor in chronic obstructive bronchitieg
Ibid., 1, 1073 . 